\title{
Molecular mechanisms involved in human platelet aggregation by synergistic interaction of platelet-activating factor and 5- hydroxytryptamine
}

\author{
Bukhtiar H. Shah ${ }^{1,2}$, Huma Rasheed, \\ Ibrahim H. Rahman', Amir H. Shariff', \\ Fatima L. Khan ${ }^{1}$, Hina B. Rahman ${ }^{1}$, Sara Hanif ${ }^{1}$ \\ and Sheikh A. Saeed ${ }^{1,3}$
${ }^{1}$ Department of Biological and Biomedical Sciences, The Aga Khan University, Karachi-74800, Pakistan
${ }^{2}$ Present address: ERRB/NICHD. National Institutes of Health, Bethesda, MD, 20892, USA
${ }^{3}$ Corresponding author: Fax, +92-21-4934294

Accepted 24 November 2001

Abbreviations: $\left(\mathrm{Ca}^{2+}\right)$; calcium, COX, cyclooxygenase; ERK1/2, extracellularly regulated mitogen-activated protein kinases; 5-HT, 5hydroxytryptamine; NO, nitric oxide; PAF, platelet-activating factor; PKC, protein kinase C; PLC, phospholipase C; PI 3-kinase, phosphatidylinositol 3-kinase; $\mathrm{TXA}_{2}$, thromboxane $\mathrm{A}_{2}$

\begin{abstract}
Our recent studies have shown that co-activation of $G_{q}$ and $G_{i}$ proteins by 5-hydroxytryptamine (5-HT) and adrenaline show synergism in human platelet aggregation. This study was conducted to examine the mechanism(s) of synergistic interaction of 5-HT and platelet activating factor (PAF) in human platelets. We show that PAF, but not 5-HT, increased platelet aggregation in a concentration-dependent manner. However, low concentrations of 5-HT ( $2 \mu \mathrm{M})$ potentiated platelet aggregation induced by subthreshold concentration of PAF (40 nM) indicating a synergistic interaction between the two agonists and this synergism was blocked by receptor antagonists to either 5-HT or PAF. 5-HT also potentiated the effect of PAF on thromboxane $A_{2}\left(T_{\left.X A_{2}\right)}\right.$ formation and phosphorylation of extracellularly regulated mitogen-activated protein kinases (ERK1/2). The synergism of 5-HT and PAF in platelet aggregation was inhibited by calcium $\left(\mathrm{Ca}^{2+}\right)$ channel blockers, verapamil and diltiazem, phospholipase C (PLC) inhibitor, U73122, cyclooxygenase (COX) inhibitor, indomethacin, and MEK inhibitor, PD98059. These data suggest that synergistic effect of 5-HT and PAF on human platelet aggregation involves activation of
\end{abstract}

\author{
PLC/Ca ${ }^{2+}, \mathrm{COX}$ and MAP kinase pathways.
}

Keywords: platelet aggregation, PAF, 5-HT, MAP kinase, synergism

\section{Introduction}

Platelets play an important role in maintaining the vascular integrity and haemostasis. Upon vascular damage, platelets undergo rapid changes; become more spherical, extrude pseudopodia and activate their fibrinogen receptors leading to aggregation. During this process, platelets release granule contents and substances that act in autocrine fashion to further enhance aggregation (Siess, 1989; Brass et al., 1993). We, and others have shown that various platelet agonists at low concentrations elicit synergistic interactions (Ware et al., 1987; Shah and Saeed, 1995; Saeed et al., 1997; Masini et al., 1998; Shah et al., 1999; Francesconi et al., 2000). However, the molecular basis of such an interaction is not well understood.

Most of the platelet agonists, like thrombin, ADP, PAF, epinephrine and 5-HT, interact with their transmembrane receptors on platelets coupled to GTP binding proteins ( $\mathrm{G}$ proteins). The $\mathrm{G}$-proteins mediate a variety of cellular processes by activating different effector molecules, including adenylyl cyclase, inositol phospholipid-specific phospholipase C (PLC) or ion channels (Siess et al., 1989; Exton, 1996). In platelets, stimulation of receptors coupled to $\mathrm{G}_{\mathrm{q}}$ protein (e.g., by 5-HT, PAF or thrombin) leads to activation of PLC and thus generation of second messengers, diacylglycerol (DAG) and inositol-1,4,5-triphosphate $\left(\mathrm{IP}_{3}\right)$, which results in the activation of protein kinase $C(P K C)$ and the mobilization of intracellular $\mathrm{Ca}^{2+}$, respectively (Obberghen-Schilling and Pouyssegur, 1993). Both $\mathrm{Ca}^{2+}$ and PKC stimulate platelet aggregation and also elicit synergism in platelets (Crabos et al., 1992). Consistent with the potential involvement of $G_{q} / P L C$ pathway, the deficiency of $G_{q}$ protein in transgenic mice leads to impairment of agonistinduced platelet aggregation (Offermans et al., 1997).

PAF, a phospholipid mediator, is a very strong platelet activator and human platelets show high affinity binding sites for this agonist. It also induces adhesion of platelets to the endothelium in the presence of activated leukocytes (Hirafuji and Shinoda, 1991). PAF is also known to play an important role in various patho- 
physiological conditions that include modulation of blood pressure, hypotension, cardiac dysfunction in cardiac anaphylaxis, and hemorrhagic, traumatic, and septic shock syndromes (Anderson et al., 1991; Montrucchio et al., 2000). Because of its ability to stimulate endothelial migration and angiogenesis, a potential role of PAF in atherosclerosis was suggested (Montrucchio et al., 2000). $\mathrm{PAF}$ is also known as a potent stimulator of thromboxane $A_{2}\left(T X A_{2}\right)$ production in human platelets.

Another platelet agonist, 5-hydroxytryptamine (5-HT), is released by aggregating platelets at the site of vascular damage and this process can be augmented by PAF (Bailey et al., 2000). 5-HT is widely distributed in the body and sub-serves many functions. The type 2 receptors for $5-\mathrm{HT}\left(5-\mathrm{HT}_{2}\right)$ mediate many physiological functions that include increase in arterial constriction, modulation of perception, mood, feeding behaviour, and platelet aggregation (Roth et al., 1998; Robertson, 1991). Very little $5-\mathrm{HT}$ is free in plasma, most being stored in dense granules of platelets. However, local platelet activation and subsequent 5-HT release can present free 5$\mathrm{HT}$ to peripheral tissues that can contribute to a range of cardiovascular problems, including portal hypertension (Robertson, 1991) and vasoconstriction (Roth et al., 1998). High plasma 5-HT levels are found in primary pulmonary hypertension (Kereveur et al., 2000) and in patients with bladder cancer (Pawlak et al., 2000). Similarly $5-\mathrm{HT}_{2 \mathrm{~A}}$ receptor densities tend to increase in depression (Mendelson, 2000). Like PAF, 5-HT also shows mitogenic effects in cardiovascular system (Koba et al., 2000). It enhances the atherogenic and mitogenic effects of low-density lipoproteins (LDL) in aortic smooth muscles (Koba et al., 2000). Combined TXA ${ }_{2}$ and 5- $\mathrm{HT}_{2}$ receptor blockade is proposed to prevent coronary artery thrombosis (Willerson et al., 1990).

PAF enhances vasoconstriction of the coronary arterioles (DeFily et al., 1996) and at the inflammatory coronary lesions in vivo by itself as well as in a synergistic manner with 5-HT (Kozai et al., 1997). Because of the close interaction between the two agonists (PAF and 5$\mathrm{HT}$ ) and their importance in thrombosis, hypertension and atherosclerosis, this study was conducted to examine the mechanism(s) of synergism between 5-HT and PAF during platelet aggregation. We show that synergistic interaction of $5-\mathrm{HT}$ and PAF is mediated through $\mathrm{PLC} / \mathrm{Ca}^{2+}$ and cyclooxygenase pathways and is modulated by nitric oxide.

\section{Materials and Methods}

\section{Materials}

PAF, 5-HT, cyproheptadine methysergide, indomethacin, diltiazem, verapamil, chelerythrine and wortmannin were purchased from the Sigma Chemical Co. (St. Louis, MO. USA). U73122 and SNAP were from Alexis LC
Labs (UK). All other chemicals were of the highest purity grade available.

\section{Preparation of human platelets}

Blood was taken by venous-puncture from normal human volunteers reported to be free of medication for one week. Blood samples were mixed with $3.8 \%(w / v)$ sodium citrate solution (9:1) and centrifuged at $260 \mathrm{~g}$ for $15 \mathrm{~min}$ at $20^{\circ} \mathrm{C}$ to obtain platelet rich plasma (PRP). Platelet count was determined by phase contrast microscopy and all aggregation studies were carried out at $37^{\circ} \mathrm{C}$ with PRP having platelet counts between 2.5 and $3.0 \times 10^{8} / \mathrm{ml}$ of plasma (Saeed et al., 1997).

\section{Measurement of platelet aggregation}

Aggregation was monitored using a Dual-channel Lumi-aggregometer (Model 400 Chronolog Corporation, Chicago, USA) using $0.45 \mathrm{ml}$ aliquots of PRP. The final volume was made up to $0.5 \mathrm{ml}$ with the test drug dissolved either in normal saline or appropriate vehicle known to be devoid of any effect on aggregation. Aggregation was induced with PAF and sub-threshold concentration determined. To obtain the synergistic effect of PAF and 5-HT, we added low concentrations of these agonists. The anti-aggregatory effects of different compounds were studied by pretreatment of PRP with various inhibitors for one min followed by addition of the sub-threshold concentrations of PAF and 5-HT. The resulting aggregation was recorded for $5 \mathrm{~min}$ after challenge by the change in light transmission as a function of time. Once the anti-platelet activity of various inhibitors against agonists was established, dose-response curves were constructed to calculate the $I_{50}$ values of the agonists and inhibitors.

\section{Thromboxane formation in platelets}

Arachidonic acid metabolism and thromboxane A2 (TXA $)$ formation were studied as described previously (Saeed et al., 1997). For these studies, human blood platelets were routinely obtained in plastic bags containing 30-40 $\mathrm{ml}$ of concentrated PRP from The Aga Khan University Hospital Clinical laboratory, Karachi.

\section{Immunoblot analysis of ERK1/2}

Platelets were stimulated with PAF at $37^{\circ} \mathrm{C}$, lysed with an equal volume of $2 \times$ Laemmli's sample buffer containing $5 \% \beta$-mercaptoethanol. The samples were heated at $95^{\circ} \mathrm{C}$ for 5 minutes, electrophoresed on SDSPAGE $(10 \%)$ gels and transferred to PDVF nylon membranes. Membranes were incubated overnight with phospho-MAP kinase (p42/44) primary antibody (New England Biolabs) diluted in TBST. Primary antibody was removed and blots washed three times with TBST before adding the horseradish peroxidase-conjugated secondary antibody for $1 \mathrm{~h}$ at room temperature. After 
washing six times with TBST, blots were exposed to enhanced chemiluminescence reagent (Amersham Pharmacia) and films developed.

\section{Results}

Treatment of PRP with PAF showed concentrationdependent aggregatory effects on human platelets
(Figure 1A). In contrast, 5-HT had no effect on platelet aggregation up to $200 \mu \mathrm{M}$ (data not shown). But very low concentrations of $5-\mathrm{HT}(2 \mu \mathrm{M})$ caused marked potentiation of aggregation response mediated by subthreshold concentration of PAF $(40 \mathrm{nM})$ suggesting a synergism between the two agonists (Figure 1B). To examine the molecular basis of this synergism, we used the selective inhibitors of various signalling pathways. Pretreatment of PRP with 5-HT receptor antagonist,
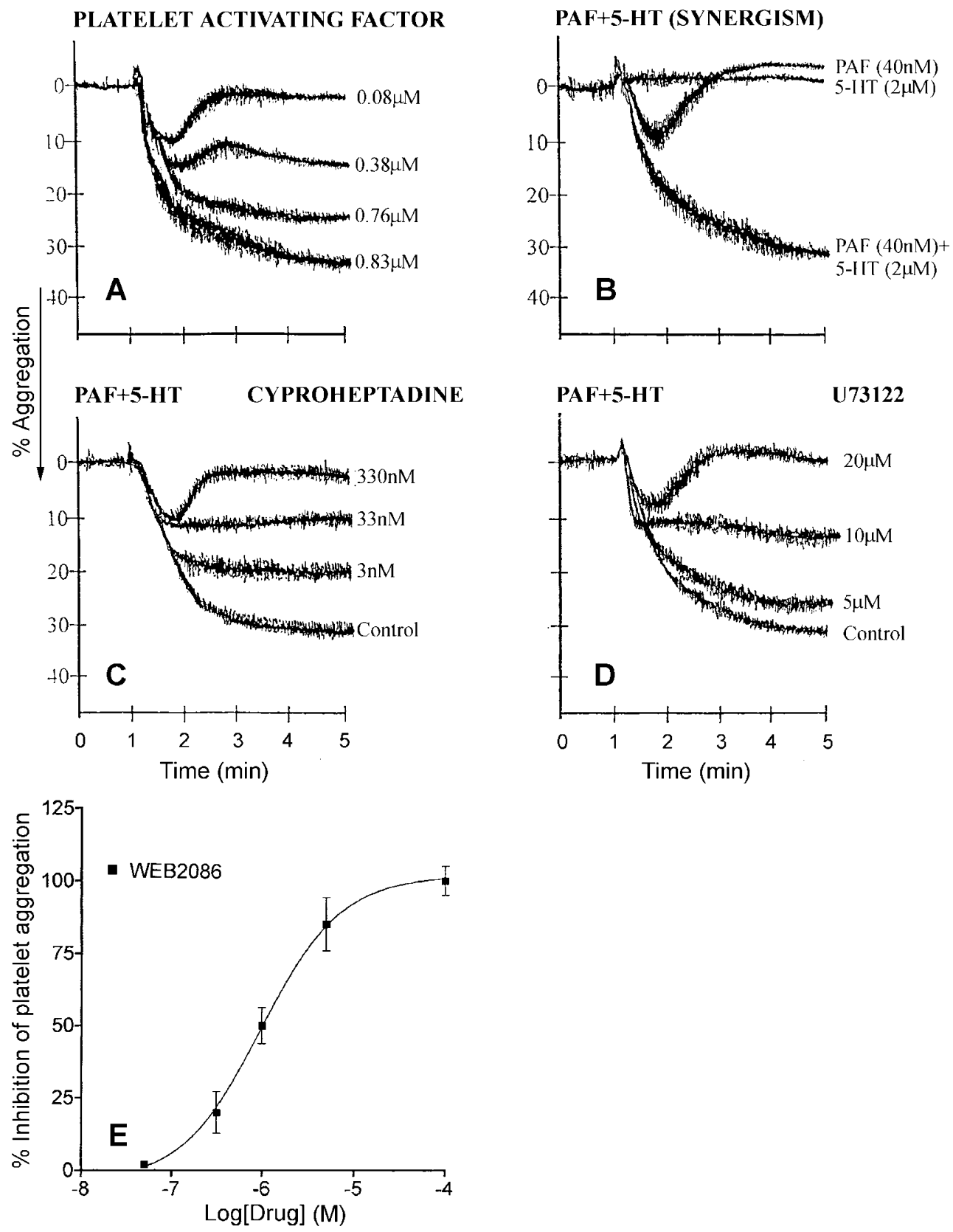

Figure 1. (A) Concentration-dependent effects of PAF on human platelet aggregation. PRP was treated with the agonist and platelet aggregation recorded for 5 min. (B) Tracings from representative experiments showing synergism of $5-\mathrm{HT}(2 \mu \mathrm{M})$ and PAF $(40 \mathrm{nM})$. (C) The synergistic effect of 5-HT and PAF on platelet aggregation is blocked by 5-HT receptor antagonist, cyproheptadine (D) phospholipase C inhibitor, U73122 (E) and PAF antagonist WEB2086. Inhibitors were added one min before the agonists. Control means platelet aggregation induced by 5-HT (2 $\mu \mathrm{M})$ plus PAF (40 nM) $(n=5)$. 
Table 1. Effects of various inhibitors on platelet aggregation mediated by synergistic interaction of sub-threshold concentrations of PAF ( $40 \mathrm{nM}$ ) plus 5-HT $(2 \mu \mathrm{M})$ and PAF alone (800 nM)

\begin{tabular}{lcc}
\hline Inhibitors & PAF $+5-\mathrm{HT}$ & $\mathrm{PAF}$ \\
& $\mathrm{IC}_{50}$ values $(\mu \mathrm{M})$ & $\mathrm{IC}_{50}$ values $(\mu \mathrm{M})$ \\
\hline Cyproheptadine & ${ }^{*} 4.00 \pm 0.02$ & ${ }^{*} 40 \pm 4.5$ \\
Methysergide & ${ }^{*} 55.00 \pm 2.2$ & $52 \pm 3.4$ \\
WEB 2086 & $0.50 \pm 0.08$ & $48 \pm 5.5$ \\
Verapamil & $8.00 \pm 0.1$ & $20 \pm 3.4$ \\
Diltiazem & $5.20 \pm 0.4$ & $15 \pm 2.0$ \\
PD98059 & $3.00 \pm 0.3$ & $4.0 \pm 0.01$ \\
Indomethacin & $0.25 \pm 0.001$ & $9 \pm 1.2$ \\
U73122 & $10.00 \pm 2.8$ & $\mathrm{NE}$ \\
SNAP & $0.28 \pm 0.04$ & $\mathrm{ND}$ \\
Wortmannin & $0.62 \pm 0.10$ & $\mathrm{ND}$ \\
\hline
\end{tabular}

Data is mean \pm SEM $(n=5-7)$ and is indicated as half-maximal effect $\left(\mathrm{IC}_{50}\right)$ of the inhibitors. ( $\left.{ }^{*}\right)$ Means concentrations in $\mathrm{nM}$. (NE = no effect and $\mathrm{ND}=$ not done)

cyproheptadine $\left(\mathrm{IC}_{50}=4 \mathrm{nM}\right)$ was effective in blocking synergism of 5-HT and PAF (Figure 1C). Consistent with the notion that both PAF and $5-\mathrm{HT}$ activate $\mathrm{G}_{\mathrm{q}} / \mathrm{PLC}$, pretreatment of PRP with PLC inhibitor, U73122, completely inhibited the synergistic effect of PAF and 5-HT with an $\mathrm{IC}_{50}$ of $10 \pm 3 \mu \mathrm{M}$ (Figure 1D).

Like cyproheptadine, PAF receptor antagonist WEB $2086\left(\mathrm{IC}_{50}=0.5 \mu \mathrm{M}\right)$ also showed marked inhibition indicating that the synergistic effect of 5-HT and PAF was dependent on functional receptors for both agonists (Figure 1E). Since activation of PLC leads to an increase in cytosolic $\mathrm{Ca}^{2+}$ due to its release from internal stores by inositol triphosphate $\left(\mathrm{IP}_{3}\right)$ or through storedepleted $\mathrm{Ca}^{+2}$-influx (Heemskerk and Sage, 1994), we examined the effect of $\mathrm{Ca}^{2+}$ channel blockers (verapamil and diltiazem) on platelet aggregation. The synergistic effect of low concentrations of PAF (40 nM) and 5-HT (2
TXA2 production by PAF and 5-HT

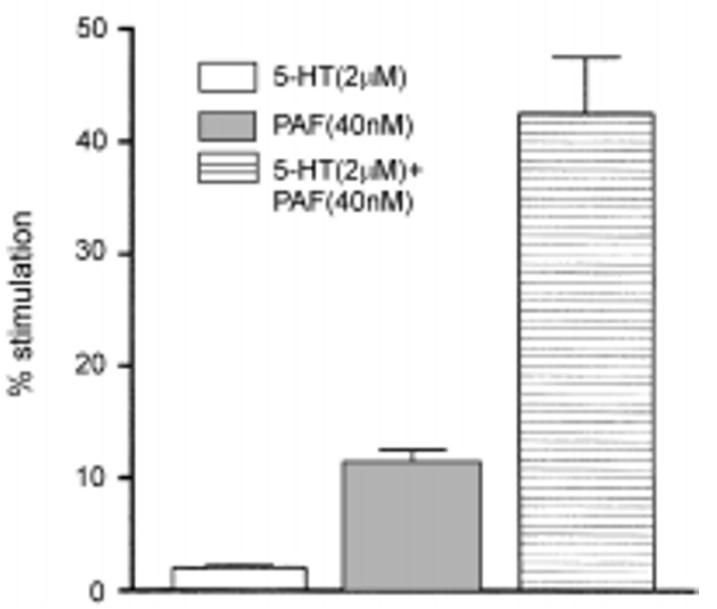

Figure 2. Effects of 5-HT and PAF on thromboxane $\mathrm{A} 2\left(\mathrm{TXA}_{2}\right)$ formation in human platelets. Low concentrations of $5-\mathrm{HT}(2 \mu \mathrm{M})$ potentiate the effect of PAF (40 nM) on $\mathrm{TXA}_{2}$ formation in human platelets $(n=7)$.

$\mu \mathrm{M})$ was markedly inhibited by low concentrations of verapamil and diltiazem with $\mathrm{IC}_{50}$ of 5 and $8 \mu \mathrm{M}$, respectively (Table 1). In contrast, PKC inhibitor, chelerythrine, had no inhibitory effect, excluding any role of PKC in this cascade (data not shown). These data suggest that platelet aggregation mediated by co-addition of subthreshold concentrations of these agonists predominantly is $\mathrm{Ca}^{2+}$-dependent and also occurs through influx of calcium through receptor-operated calcium channels.

PAF is considered to be a potent activator of TXA2 formation through activation of cyclooxygenase-1 (COX1). To examine if these two agonists show synergism on COX-1 activity, we measured TXA2 formation in agonisttreated platelets. Similar to its effect on platelet aggregation, 5-HT markedly potentiated the TXA2 formation
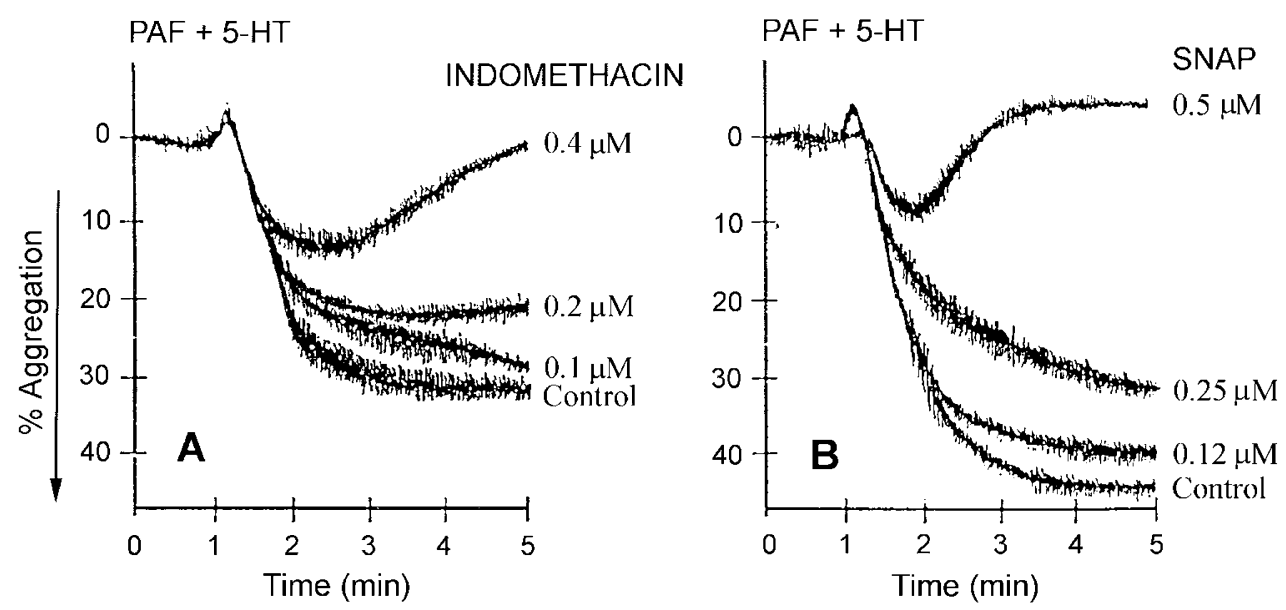

Figure 3. (A) Cyclooxygenase (COX) inhibitor, indomethacin, (B) Nitric oxide donor, SNAP, inhibits platelet aggregation induced by co-addition of sub-threshold concentrations of $5-\mathrm{HT}$ and PAF. Inhibitors were added one min before the addition of agonists. Control means platelet aggregation induced by $5-\mathrm{HT}(2 \mu \mathrm{M})$ plus PAF $(40 \mathrm{nM})(\mathrm{n}=7)$. 
by low concentrations of PAF $(40 \mathrm{nM})$ as shown in Figure 2. Moreover, the selective COX-1 inhibitor, indomethacin, completely blocked platelet aggregation at very low concentrations $\left(\mathrm{IC}_{50}=0.25 \mu \mathrm{M}\right)$ suggesting the potential involvement of COX-1 in this synergism (Figure $3 A$ ). Recent studies indicate an important role of nitric oxide (NO) in modulating platelet aggregation (Shah et al., 1999). An analysis of results show that NO donor, SNAP, completely blocked platelet aggregation mediated by synergistic interaction of PAF and 5-HT (Figure 3B). These data provide evidence in support of an important role for $\mathrm{NO}$ in negatively modulating the human platelet aggregation.

Agonist-stimulation of $\mathrm{G}_{\mathrm{q}} / \mathrm{PLC} / \mathrm{Ca}^{+2}$ cascade leads to activation of mitogen-activated protein (MAP) kinases (Della Roca et al., 1999; Heemskerk and Sage, 1994). We have recently shown that synergism of adrenaline and histamine involves phosphorylation of extracellularly regulated MAP kinases (Shah et al., 2000). Results in Figure 4A show that PAF stimulated the phosphorylation of ERK1/2 and 5-HT increased this effect. Pretreatment

A
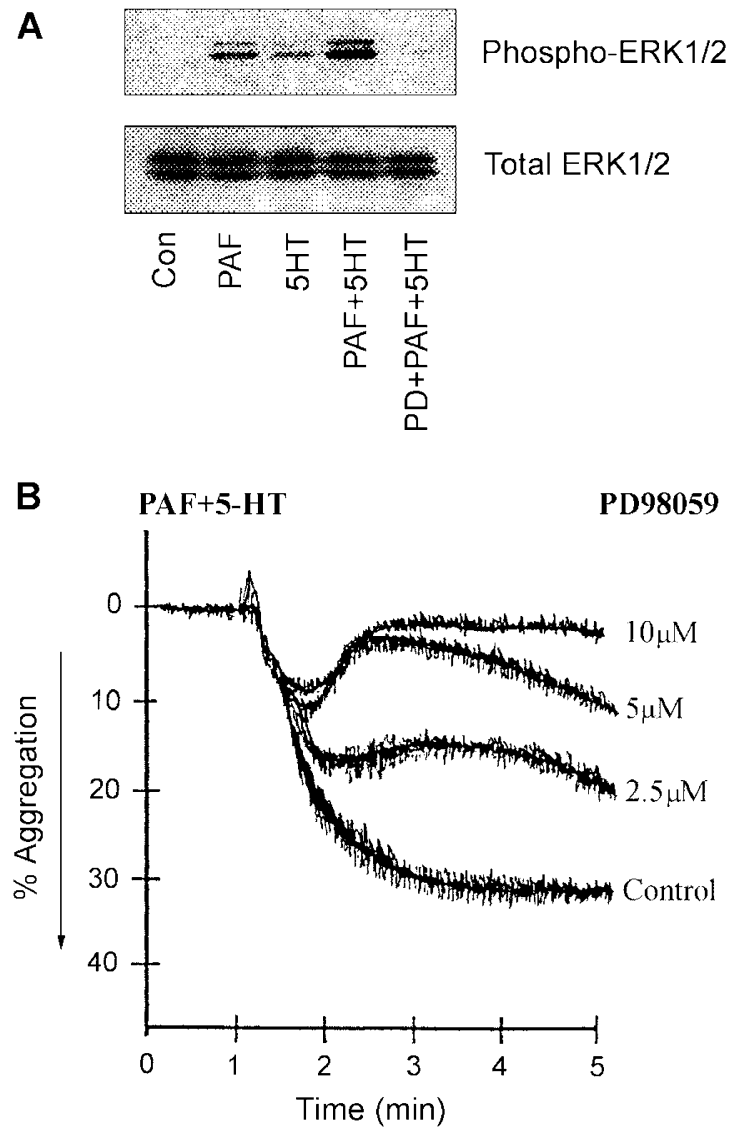

Figure 4. (A) Effects of 5-HT and PAF on the phosphorylation of extracellularly regulated MAP kinases (ERK1/2) in human platelets. PD98059 blocks the ERK $1 / 2$ activation. (B) Concentration-dependent effects of MEK inhibitor, PD98059, on platelet aggregation induced by co-addition of 5-HT and PAF. Control means platelet aggregation induced by $5-\mathrm{HT}(2 \mu \mathrm{M})$ plus PAF $(40 \mathrm{nM})(\mathrm{n}=6)$. of PRP with MEK inhibitor, PD98059, inhibited ERK1/2 activation induced by co-addition of sub-threshold concentrations of PAF and 5-HT. Similarly, PD98059 also inhibited platelet aggregation in response to agonist synergism (Figure 4B). Since MEK inhibitor, PD98059, is reported to directly inhibit purified COX-1 and -2 (Borsch-Haubold et al., 1998), we examined the effect of PD98059 on arachidonic acid metabolism and TXA formation. An analysis of results show that PD98059 also inhibits agonist-induced $\mathrm{TXA}_{2}$ production with an $\mathrm{IC}_{50}$ of $5 \pm 0.3 \mu \mathrm{M}$. Thus, it is possible that the inhibitory effect of PD98059 on platelet aggregation is mediated through inhibition of COX activity. We also examined the effect of inhibitors against PAF alone and the data is given in Table 1. Our results show that inhibitors of various signalling pathways inhibited PAF plus 5-HT induced aggregation at lower $\mathrm{IC}_{50}$ values as compared to the $\mathrm{IC}_{50}$ values obtained against PAF alone (Table 1).

Phosphatidylinositol 3-kinase (PI 3-kinase), is activated by GPCRs and growth factors, and plays an important role in platelet aggregation. The selective inhibitor of $\mathrm{PI}$ 3-kinase, wortmannin, is reported to block the aggregation response induced by synergism of $5-\mathrm{HT}$ and adrenaline (Shah and Saeed, 1995). Our results show that wortmannin inhibited platelet aggregation $\left(\mathrm{IC}_{50}=620\right.$ $\mathrm{nM}$ ) induced by the synergism of PAF and $5-\mathrm{HT}$ (Table 1).

\section{Discussion}

Most of the platelet agonists, which interact with Gprotein coupled receptors, exert their effects through activation of either $\mathrm{G}_{\mathrm{q}} / \mathrm{PLC}$ (e.g. PAF, thrombin) or $\mathrm{G}_{\mathrm{i}} /$ adenylyl cyclase (e.g., adrenaline) in platelets (Siess et al., 1989; Brass et al., 1993). The second messengers, $\mathrm{Ca}^{2+}$ and PKC generated in response to $\mathrm{G}_{\mathrm{q}} / \mathrm{PLC}$ activation bring about coordinated changes leading towards platelet aggregation (Crabos et al., 1992; Heemskerk and Sage, 1994). The platelet aggregation by sub-threshold concentrations of PAF and 5-HT were inhibited by receptor antagonists, and inhibitors of PLC and MAP kinase and Cox. We (Shah et al., 1999; 2000), and others have recently shown that concomitant activation of $G_{i}$ and $G_{q}$ protein-linked signalling pathways results in aggregation of human platelets. However, the present data demonstrate that activation of $\mathrm{G}_{\mathrm{q}}$ protein by two different agonists at sub-threshold concentrations is equally potent in eliciting the aggregation response by platelets.

In platelets, PAF and 5-HT cause stimulation of $\mathrm{G}_{\mathrm{q}}$ protein followed by activation of PLC. This explains why U73122, a selective inhibitor of PLC, shows strong inhibitory effects on platelet aggregation induced by coactivation by these agonists. Further, PLC activation leads to generation of $\mathrm{IP}_{3}$, release of $\mathrm{Ca}^{2+}$ from internal 
stores and eventually store-depleted $\mathrm{Ca}^{2+}$ influx (Heemskerk and Sage, 1994) that was inhibited by $\mathrm{Ca}^{2+}$ channel blockers (verapamil and diltiazem). Moreover, the increase in cytosolic $\mathrm{Ca}^{2+}$ causes activation of $\mathrm{PLA}_{2}$ and COX-1 activity, thus stimulating $\mathrm{TXA}_{2}$ formation (Heemskerk and Sage, 1994). Since the synergism of these agonists was inhibited by indomethacin, a COX-1 inhibitor, it seems that the agonist-mediated synergism follows activation of COX- 1 distal to $\mathrm{PLC} / \mathrm{Ca}^{2+}$ activation. We tested if increasing the intracellular nitric oxide (NO) levels by NO donor and thus activating cGMP kinase has any inhibitory effect on platelet aggregation. Our results show that NO donor, SNAP, inhibited platelet aggregation at very low concentrations $\left(\mathrm{IC}_{50}=0.3 \mu \mathrm{M}\right)$ suggesting that PAF and 5-HT synergism is highly sensitive to $\mathrm{NO}$ generation in human platelets (Figure 3B). However, the role of PKC in the present study was excluded as PKC inhibition had no effect on the synergism of PAF and 5-HT in platelets.

The cyclic nucleotides, cAMP and cGMP, through activation of CAMP- and cGMP-dependent protein kinases, down-regulate the $\mathrm{Ca}^{2+}$ responses and thus inhibit platelet aggregation (Heemskerk and Sage, 1994). In fact platelets are abundant in CAMP and cGMP-dependent protein kinases and these kinases can inhibit PLCinduced $\mathrm{IP}_{3}$ production through inactivation of $\mathrm{IP}_{3}$ and $\mathrm{TXA}_{2}$ receptors (Heemskerk and Sage, 1994; Wang et al., 1998).

The inhibition of PAF/5-HT synergism by MEK inhibitor, PD98059, suggests the involvement of MAP kinase that is known to be distal to Gq/PLC (Della Roca et al., $1997 ; 1999)$. PAF through activation of $\mathrm{G}_{\mathrm{q}} / \mathrm{PLC}$ is reported to activate ERK1/2 MAP kinases through different signalling pathways that include PI 3-kinase, tyrosine kinases such as proline-rich tyrosine kinase (Pyk2), Ras/Raf and MEK1/2 (Ishii and Shimizu, 2000; Miike et al., 2000). ERK1/2 phosphorylation can activate $\mathrm{CPLA}_{2}$ leading to production of prostaglandins and $\mathrm{TXA}_{2}$ through activation of COX (Ishii and Shimizu, 2000). In fact, CPLA2 is also a potential target of activation by increase in cytosolic $\mathrm{Ca}^{2+}$. Taken together, it appears as both $\mathrm{Ca}^{2+}$ and MAP kinases play an important role during synergistic interaction of 5-HT and PAF in human platelets.

The selective MEK inhibitor, PD98059, is also known to inhibit the COX-1 and -2 activities (Borsch-Haubold et al., 1998; McNicole et al., 1998). Using purified COX-1 and -2, Borsch-Haubold et al., (1998) showed that PD98059 inhibited arachidonic acid metabolism and $\mathrm{TXA}_{2}$ formation at quite low concentrations $\left(\mathrm{IC}_{50}=0.8\right.$ $\mu \mathrm{M})$. These authors reported that higher concentrations of PD98059 were required to inhibit platelet aggregation induced by arachidonic acid, thrombin and collagen. Under our experimental conditions, PD98059 inhibited both $\mathrm{TXA}_{2}$ production and platelet aggregation with $\mathrm{IC}_{50}$ of 5 and $3 \mu \mathrm{M}$, respectively (Figures $4 \mathrm{~A} \& \mathrm{~B}$ ). There- fore, the possibility that inhibition of agonist-induced platelet aggregation by PD98059 is due to blockade of COX activity cannot be ignored.

Our previous studies have shown an important role of $\mathrm{PI}$ 3-kinase in 5-HT mediated potentiation of platelet aggregation by adrenaline (Shah and Saeed, 1995). In addition, the inhibitors of PI 3-kinase block platelet aggregation induced by low, but not high, concentrations of PAF (Lauener et al., 1999). More recently, PI 3-kinase was shown to be involved in the thrombopoietin (TPO) mediated potentiation of platelet function. TPO stimulated ERK1/2 MAP kinase activation by increasing the association of tyrosine phosphorylated Gab1 with p85 subunit of PI 3-kinase. Our data show that PI 3-kinase inhibitor, wortmannin, abolished platelet aggregation only at higher concentrations $(1 \mu \mathrm{M})$. Since higher concentrations of wortmannin (>100 $\mathrm{nM}$ ) are known to inhibit other signaling proteins such as myosin light chain kinase, in platelets, the involvement of PI 3-kinase in this cascade cannot be over-emphasized.

The mechanism of synergism among various platelet agonists is reported to occur due to activation of $\mathrm{Ca}^{2+}$ signalling cascade. $\mathrm{A}$ rise in $\mathrm{Ca}^{2+}$ induced by first agonist primes platelets for an enhanced functional response to the second agonist (Ware et al., 1987; Shah et al., 1999). $\mathrm{Ca}^{2+}$ plays pivotal role in platelet aggregation (Heemskerk and Sage, 1994; Shah et al., 1998). Interruption in the process of $\mathrm{Ca}^{2+}$ activation either through $\mathrm{Ca}^{2+}$ channels (Shah et al., 1998) or $\mathrm{G}_{\mathrm{q}}$ proteins can

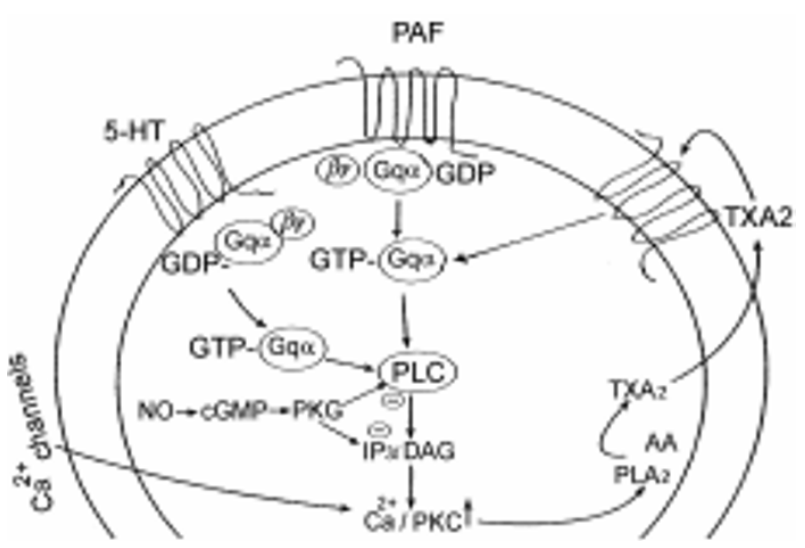

Figure 5. Signalling pathways involved in the synergistic interaction of GPCR agonists, 5-HT and PAF. Both agonists activate phosphoinositidelinked $\mathrm{G}$ protein $(\mathrm{Gq})$ and phospholipase C (PLC), which leads to generation of inositol triphosphate $\left(\mathrm{IP}_{3}\right)$ and diacylglycerol $(\mathrm{DAG})$, and thus release of $\mathrm{Ca}^{2+}$ from internal stores and activation of protein kinase C (PKC). The agonist-induced store-depletion of $\mathrm{Ca}^{2+}$ also increases $\mathrm{Ca}^{2+}$ influx through membranes. Both $\mathrm{Ca}^{2+}$ and PKC are involved in the release of granule contents and activation of phospholipase $\mathrm{A} 2\left(\mathrm{PLA}_{2}\right)$, thus generation of potent agonist, thromboxane $A_{2}\left(T X A_{2}\right)$, which in an autocrine fashion acts on platelets through $\mathrm{Gq}$ protein. Nitric oxide (NO) inhibits platelet aggregation through production of cyclic GMP (cGMP) from guanylate cyclase. The cGMP activates protein kinase $G$ (PKG) that exerts inhibitory effect on platelet aggregation through phosphorylation of $\mathrm{PLC}, \mathrm{Ca}^{2+}$-channels or $\mathrm{IP}_{3^{-}}$ receptor. 
interfere with the activation of platelets. Offermanns et al. (1999) showed that $G_{q}$ protein-deficient mice lack the ability of platelet aggregation. Co-activation of PAF and 5-HT receptors on platelets seems to follow the $\mathrm{G}_{\mathrm{q}} / \mathrm{PLC} /$ $\mathrm{Ca}^{2+}$, and inhibitors of PLC, MAP Kinase and COX, (Figure 5). The synergism among various platelet agonists in the body is of great clinical significance as it can lead to marked potentiation of the platelet activation and thus alter the cardiovascular physiology. In conclusion, our studies show that sub-threshold concentrations of 5-HT potentiate the platelet aggregation mediated by PAF in vitro, and this synergism is negatively modulated by nitric oxide donor, SNAP, suggesting a potential regulatory role of nitric oxide in platelet function.

\section{Acknowledgements}

This study was supported by the research funds from the Aga Khan University, Karachi.

\section{References}

Anderson BO, Bensard DD, Harken AH. The role of platelet activating factor and its antagonists in shock, sepsis and multiple organ failure. Surg Gynecol Obstet 1991;172:415-24

Bailey SR, Andrews MJ, Elliott J, Cunningham F. Actions and interactions of ADP, 5-HT, histamine and PAF on equine platelets. Res Vet Sci 2000;68:175-80

Borsch-Haubold AG, Pasquet S, Watson SP, Direct inhibition of cyclooxygenase- 1 and -2 by the kinase inhibitors $S B$ 203580 and PD 98059. J Biol Chem 1998;273:28766-72

Brass LF, Hoscie JA, Manning DR, Signalling through G proteins and $G$ protein-coupled receptors during platelet activation. Thromb Haemost 1993;70:217-23

Crabos M, Fabbro D, Stabel S, Erne P. Effect of tumorpromoting phorbol ester, thrombin and vasopressin on translocation of three distinct protein kinase $C$ isoforms in human platelets and regulation by calcium. Biochem $\mathrm{J}$. 1992;288:891-96

DeFily DV, Kuo L, Chilian WM. PAF attenuates endotheliumdependent coronary arteriolar vasodilation. Am J Physiol 1996;270:H2094-99

Della Rocca GJ, Biesen TV, Daaka Y, Luttrell KD, Luttrell LM, Lefkowitz RJ. Ras-dependent mitogen-activated protein kinase activation by $\mathrm{G}$ protein-coupled receptors. J Biol Chem 1997;272:19125-32

Della Rocca GJ, Mausley S, Daaka Y, Lefkowitz RJ, Luttrell LM. Pleiotropic coupling of $G$ protein-coupled receptors to the mitogen-activated protein kinase cascade. Role of focal adhesions and receptor tyrosine kinases. J Biol Chem 1999;274:13978-84

Exton JH. Regulation of phosphoinositide phospholipases by hormones, neurotransmitters, and other agonists linked to $G$ proteins. Ann Rev Pharmacol Toxicol 1996;36:481-509

Francesconi M, Scapin M, Casonato A, Girolami A, Deana R. Adrenaline potentiates type $2 \mathrm{~B}$ von Willebrand factor-induced activation of human platelets by enhancing both the formation and action of thromboxanes. Thromb Res 2000;100:293-303

Heemskerk JWM, Sage O. Calcium signalling in platelets and other cells. Platelets 1994;5:295-16

Hirafuji M, Shinoda $H$, Platelet-leukocyte interaction in adhesion to endothelial cells induced by platelet activating factor in vitro. Br J Pharamacol 1991;136:1356-77

Ishii S, Shimizu T. Platelet-activating factor (PAF) receptor and genetically engineered PAF receptor mutant mice. Progress in Lipid Res 2000;39:41-82

Kereveur A, Callebert J, Humbert M, Herve P, Simonneau G, Launay JM, Drouet L. High plasma serotonin levels in primary hypertension. Effect of long-term epoprostenol (prostacyclin) therapy. Arterioscler Thromb Vasc Biol 2000;20:2233-39

Koba S, Pakala R, Katagiri T, Benedict CR. Hyperlipemic-very low density lipoprotein, intermediate density lipoprotein and low density lipoprotein act synergistically with serotonin on vascular muscle cell proliferation. Atherosclerosis 2000;149: 61-67

Kozai T, Shimokawa H, Yamawaki T, Fukomoto Y, Kadokami T, Kuwata K, Katsumata N, Egashira K, Takeshita A. Platelet activating factor causes hypercorstriction at the inflammatory coronary lesions in pigs in vivo. Coron Artery Dis 1997;8:423432

Lauener RW, Stevens CM, Sayed MR, Salari H, Duronio V A role for phosphatidylinositol 3-kinase in platelet aggregation in response to low, but not high, concentrations of PAF or thrombin. Biochem Biophys Acta 1999;1452:197-208

Masini E, Di Bello MG, Raspanti S, Fomusi Ndisang J, Baronti $\mathrm{R}$, Cappugi $\mathrm{P}$, Mannaioni PF. The role of histamine in platelet aggregation by physiological and immunological stimuli. Inflamm Res 1998;47:211-20

McNicol A, Philpott CL, Shibou TS, Israels SJ. Effects of the mitogen-activated protein (MAP) kinase kinase inhibitor 2-(2'amino-3'-methoxyphenyl)-oxanaphthalen-4-one (PD98059) on human platelet activation. Biochem Pharmacol 1998;55: 1759-67

Mendelson SD. The current status of the platelet 5-HT(2A) receptor in depression. J Affect Disord 2000;57:13-24

Miike S, Kurasawa K, Saito Y.; Iwamoto I. Platelet-activating factor activates mitogen-activated protein kinases through the activation of phosphatidylinositol 3-kinase and tyrosine kinase in human eosinophils. J Leukoc Biol 2000;67:117-26

Montrucchio G, Alloatti G, Camussi G. Role of platelet-activating factor in cardiovascular pathophysiology. Physiological Rev. 2000;80:1669-99

Obberghen-Schilling EV, Pouyssegur J. Signalling pathways of the thrombin recepror. Thromb Haemostas 1993;70(1): $163-67$

Offermanns S, Toombs CF, Hu Y-H, Simon MI. Defective platelet activation in $\mathrm{G}_{\mathrm{q}}$-deficient mice. Nature 1997;389:183- 
86

Pawlak D, Malczyk E, Darewicz J, Azzadin A, Buczko W. Platelet serotonergic mechanisms in patients with cancer of the urianry bladder. Thromb Res 2000;98:367-74

Robertson JI. Serotonergic type-2 (5-HT2) antagonists: a novel class of cardiovascular drugs. J Cardiovascular Pharmacol 1991;17:S48-53

Roth BL, Willins DL, Kristiansen K, Kroeze WK. 5-Hydroxytryptamine-2 family receptors (5-hydroxytryptamine 2A, 5hydroxytryptamine $2 \mathrm{~B}, 5$-hydroxytryptamine $2 \mathrm{C}$ ): where structure meets function. Pharmacol. Ther. 1998;79:231-57

Saeed SA, Shah BH, Khan N, Gilani, AH. Synergistic interaction of calcium-ionophore, A-23187 and dopamine in human platelet aggregation. Med Sci Res 1997;25:219-21

Shah BH, Saeed SA. Phosphatidylinositol 3-kinase inhibitor, wortmannin, inhibits 5-hydroxytryptamine-mediated potentiation of platelet aggregation induced by epinephrine. Res Comm Mol Pathol Pharmacol 1995;89:157-64

Shah BH, Safdar B, Virani SS, Nawaz Z, Saeed SA, Gilani $\mathrm{AH}$. The antiplatelet aggregatory activity of Acacia nilotica is due to blockade of calcium influx through membrane calcium channels. Gen Pharmacol 1997;29:251-55

Shah BH, Lashari I, Rana O, Saeed O, Rasheed H, Saeed,
SA. Synergistic interaction of adrenaline and histamine in human platelet aggregation is mediated through activation of phospholipase $\mathrm{C}$ and MAP kinase and cyclooxygenase pathways. Pharmacological Res 2000;42:479-83

Shah BH, Siddiqui A, Qureshi KA, Khan M, Rafi S, Ujan VA, Yaqub Y, Rasheed H, Saeed SA. Co-activation of Gi and Gq proteins exerts synergistic effect on human platelet aggregation through activation of phospholipase $\mathrm{C}$ and $\mathrm{Ca}^{2+}$ signalling. Exp Mol Med 1999;31:42-46

Siess W. Molecular mechanisms of platelet activation. Physiol Rev 1989;69:58-78

Wang LL, Mei QB, Zhao DH, Guo ZA. Effects of MN-9202 on platelet aggregation, 5-HT release, TXB2 synthesis, and calcium mobilization in rabbit platelets in vitro. Acta Pharmacol 2000;21:23-26

Ware JA, Smith M, Salzman EW. Synergism of plateletaggregation agents: role of elevation of cytoplasmic calcium. J Clin Invest 1987;80:267-71

Willerson JT, Golino P, Eidt J, Yao S, Buja LM. Evidence that combined thromboxane A2 and serotonin receptor blockade might prevent coronary artery thrombosis and the conversion from chronic to acute coronary heart disease syndromes. Blood Coagul Fibrinolysis 1990;1:211-18 